\title{
The Olympic Forest Park wetland water quality monitoring and analysis
}

\author{
Haiqi Wei ${ }^{1, a}$, Fan Fu ${ }^{* 2, b}$, Qinglin Zhu ${ }^{3, \mathrm{c}}$,Lingfeng Shi ${ }^{4, \mathrm{~d}}$ \\ ${ }^{1,2,3,4}$ North China University of Technology,Jin Yuan Zhuang Road No. 5, \\ Shijingshan District,Beijing,China \\ a921661243@qq.com, ${ }^{\mathrm{b}} \mathrm{mattbff@163.com,,529191490@qq.com,,}{ }^{\mathrm{d}} 1837896362 @ q q . c o m$
}

\begin{abstract}
Keywords: Olympic Forest Park wetland;Water quality;Rainwater runoff pollution
Abstract. Urban constructed wetlands play an important role in water purification, water conservation, biodiversity conservation and so on. The status of the water quality and the ability to purify water quality are the important evaluation indexes to evaluate the function of constructed wetlands. Constructed wetlands are artificially designed compound that imitates the structure and function of natural wetlands. These wetlands consist of water, matrix of water saturation, aquatic plants, submerged plants, floating plants and animal etc., which achieve efficient purification of sewage through a series of biological, physical and chemical processes.Stormwater runoff erosion surface will carry a large amount of pollutants on the water pollution caused by constructed wetlands. The purpose of this study is to monitor the water quality of the Olympic Forest Park constructed wetland.Testing the effect of stormwater runoff on water of urban constructed wetland.And analyzes the reason, provides the scientific basis for the water quality of the artificial wetland in the future.
\end{abstract}

\section{Introduction}

Study Areas.The Beijing Olympic Forest Park occupies a total area of 68,000 hectares, with 12,200 hectares of water, the vast majority of which is static water. The plant coverage in this area reaches 90\%. The wetland of the Olympic Forest Park is constructed by adopting the integrated vertical-flow constructed wetland (IVCW) system developed by the Institute of Hydrobiology (IHB) of the Chinese Academy of Sciences. The selected artificial wetland in this paper is located in the west of the Southern Park of Olympic Forest Park, with an area of 4.15 hectares. The wetlands are divided into 3 parts: greenhouse education area, wetland display area and wetland experience area. The water resource of the Southern Park wetland is from the reclaimed water after treatment in Qinghe Sewage Treatment Plant and the circulating water from main lakes[1].

Monitoring Method.The hash water quality monitor (USA) is used to monitor chemical oxygen demand (COD), total nitrogen, total phosphorus, ammonia nitrogen, TSS and other indexes. Based on the Water and Waste Water Monitoring and Analysis Method, the water depth of each sampling site is set $0.5 \mathrm{~m}$. The water monitoring time is under strict control, with the sampling time being May, June and July of 2016. The sampling is conducted in the first week of each month. In case of special weather, such as rain, etc.14 monitoring sites are selected in the Olympic Forest Park.

Monitoring Point Layout.The monitoring sites are determined according to the different types of constructed wetlands of the Beijing Olympic Forest Park.According to the function and structure of constructed wetland, the monitoring points are divided.As shown in Figure 1. 


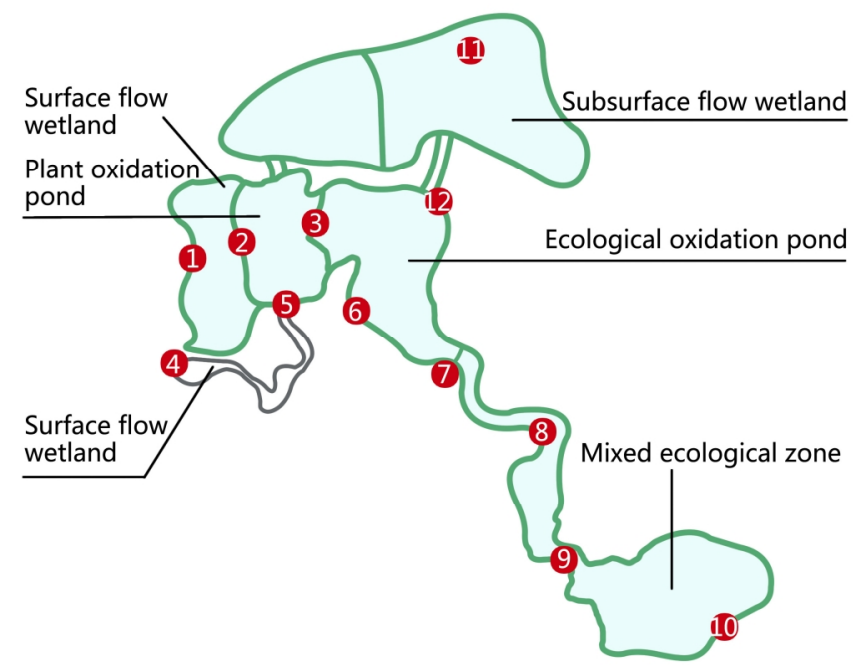

Fig 1 : Arrangement of monitoring points for artificial wetland in Olympic Forest Park

\section{Rainwater Runoff Pollution}

Surface runoff from the surface of the water flowing through the surface will cause re pollution of the surface and underground water,Surface runoff has become one of the important issues in environmental pollution because of its high pollution load and high control difficulty.

Surface runoff from the surface of the water flowing through the surface will cause re pollution of the surface and underground water,Surface runoff has become one of the important issues in environmental pollution because of its high pollution load and high control difficulty.Rain in the fall to the ground before, due to the atmospheric leaching, carrying a lot of air in the dust and a large number of pollutants.Especially prominent is the concentration of TSS and COD.When rain falls to the ground after the ground erosion runoff formation, due to ground hydrocarbons, heavy metals and other toxic pollutants, resulting in runoff to carry large amounts of pollutants, pollutant concentration will increase greatly.And the runoff pollutant concentration will change with the rain falling time and the accumulation of surface contamination.

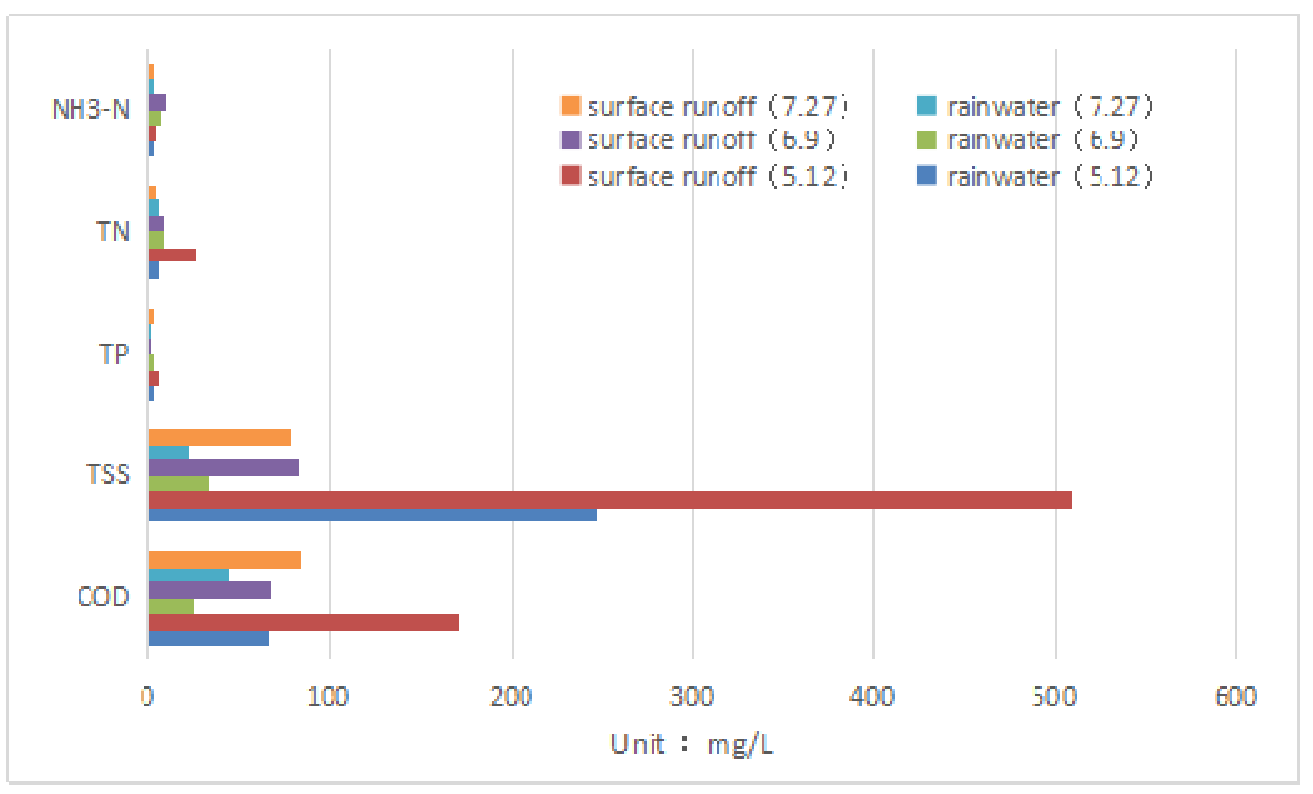

Fig 2 : Monitoring of pollutant index of storm water runoff

Figure 2 shows the results of water quality monitoring of rain and the same period in May, June, and July in 2016. The maximum concentrations of NH3-N, TN, COD and TP concentrations of the 
pollutants in rainwater were respectively reached 3.2, 4, 3.2, 1.65 times of the Class V standards in the Surface Water Environment Quality Standards of China (G3838-2002)[2].TSS up to the "Urban Sewage Recycling and Utilization of Water Quality of the Landscape Water" (18921-2002 GB/T) 12.3 times the standard of ornamental water use.Surface runoff pollutants TN, TP, NH3-N, COD concentrations of the maximum value reached 4.6, 12.9, 12.9, 4.3 times of China's $\mathrm{V}$ class standards.TSS reach 25.5 times of the standard of water consumption of ornamental environment.So the pollution caused by storm water runoff directly into the receiving water body is very serious.

\section{Monitoring results and analysis}

Measurement of pollutant concentration in the water samples of the Olympic Forest Park in May 2016.Comparison and analysis of pollutant concentration standards in the surface water environmental quality standard of China.As shown in Figure 3.It is concluded that the concentrations of NH3-N in the water of Figure 2 are in accordance with the Class IV standards.And NH3-N in the constructed wetland was increased after the rain and the 4 point of the surface flow constructed wetland was reached the peak value in May 12th and May 14th.

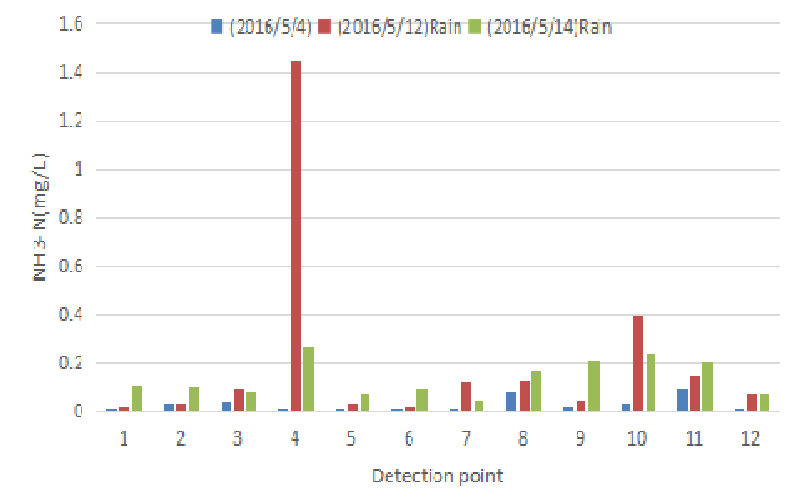

Fig $3: \mathrm{NH}_{3}-\mathrm{N}$ monitoring results

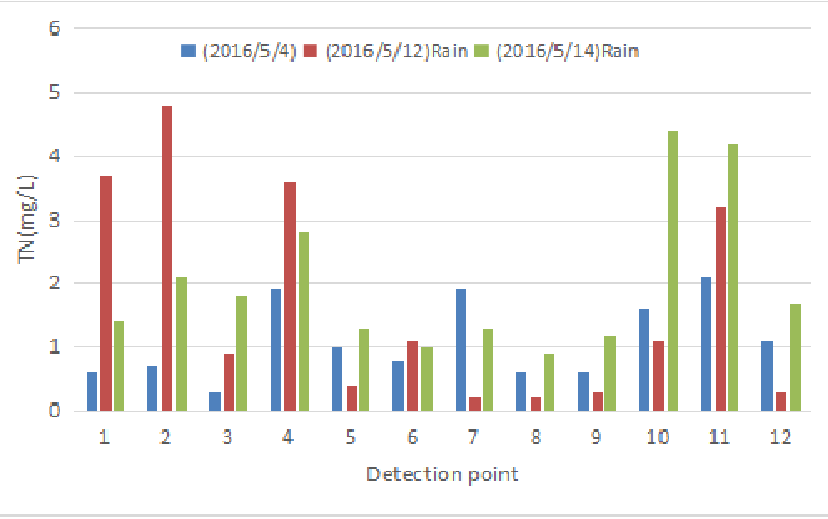

Fig 4 : TN monitoring results

Nitrogen is one of the main nutrients that lead to the eutrophication of water environment. The wetland system can remove nitrogen from water through various mechanisms, including synergy of biological, physical and chemical reactions, etc. A large number of studies have indicated that microbial nitrification and denitrification in constructed wetlands are the most important nitrogen removal mechanisms[3]. As shown in Figure 4, The total nitrogen concentration in the water is Class $\mathrm{V}$ standards in the reclaimed water inlet area and water supply region of circulating water. The TN concentration was basically in line with the Class IV standards after the process of artificial wetland.And the TN concentration was more than before the rainfall.It has the same change law with NH3-N.Again, it is proved that the runoff has a significant impact on water quality. There are similar trends in the overall change of pollutants.

Phosphorus in wetlands generally exists in the form of inorganic and organic compounds[4]. As shown in Figure 5,Total phosphorus in the water after the rain are not in line with the Class IV standards.Obviously, the influence of rainfall on the total phosphorus concentration in water quality is obvious.In sunny weather, TP is in line with Class IV standards.According to the calculation of point data.Surface flow constructed wetland, plant oxidation pond, and vertical flow constructed wetland had better removal efficiency for TP.

$\mathrm{COD}$ is an important parameter which can quickly measure the organic pollution of water, thus reflecting the pollution degree of water. The greater the value of COD, the more serious the pollution of organic matter in water[5]. As shown in Figure 6,Olympic Forest Park constructed wetland COD in sunny weather conditions are all in line with Class IV standards.But after the rain, the COD was increased obviously. Even before the rain 2.6 times. Due to the impact of rainfall almost all of the above Class IV in May 12th. The surface flow constructed wetland had a decreasing effect on COD in May 
4th.In May 12 and May 14 surface stack flow did not open drop, due to the accumulation of pollutants in stormwater, resulting in the superposition of the surface flow constructed wetland in COD concentration increased.No. 6 point backwater region ecological oxidation pond in the peak. The position of COD in the mixed ecological zone of No. 9 was also the peak value.The removal rate of COD was about $26.6 \%$ in the surface flow constructed wetlands. The removal rate of COD by surface flow constructed wetland is about $18.5 \%$. The removal rate of COD is about $31.3 \%$ in subsurface flow constructed wetland.

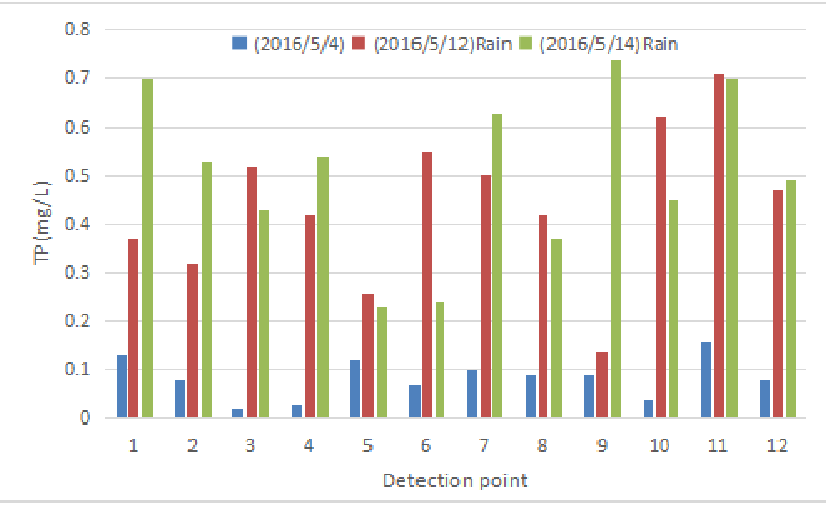

Fig 5 : TP monitoring results

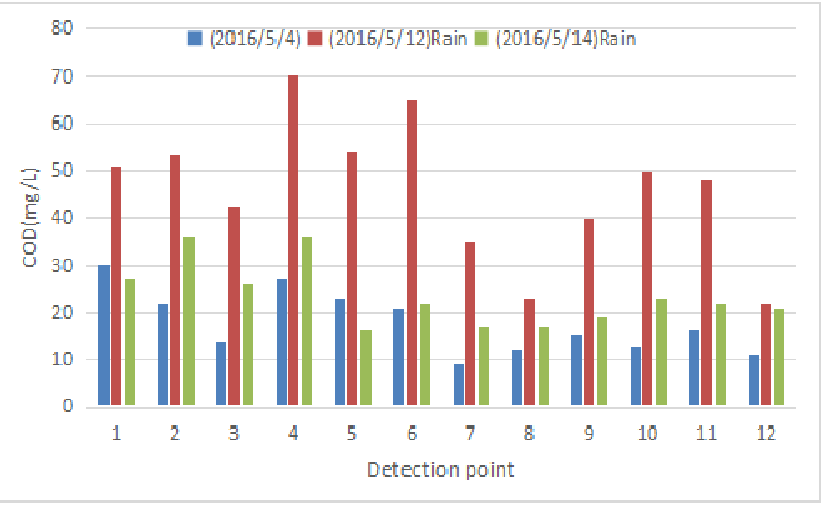

Fig 6 : COD monitoring results

\section{Conclusions}

Through monitoring of the water quality of the Olympic Forest Park constructed wetlands.Found that the water quality of artificial wetland is affected seriously by the rain. So water quality management should not only resort to the single way of water monitoring, but also pay attention to reasonable cultivation and maintenance of plant biomass. So that the use of plants, microorganisms and other pollution reduction of runoff pollution. And taking into consideration the design stage of constructing artificial wetlands, such as unsuitability of hard revetment for the artificial wetland ecosystem. In contrast, natural revetment can better interception of pollutants.In the monitoring process, solutions should also be put forward to water quality problems in a timely manner so as to create a more pleasant and more popular urban wetland with greater significance of popular science education.

\section{Acknowledgments}

This work was financially supported by Scientific Research Training program for College Students---Study on comprehensive ecological benefits of Constructed Wetland.Item status coding:(XN001-105).

\section{References}

[1] HU Jie, WU Yi- xia, LV Lu- shan,Water System Plan of Beijing Olympic Forest Park,edtied by Chinese garden,14-19(2006).

[2] The People's Republic of China Standard. GB3838-2002.

[3] LU Shao-Yong, JIN Xiang-Can,YU Gang,Nitrogen removal mechanism of Constructed Wetland,edtied by Ecological Journal,2670-2677(2006).

[4] Xing Bo,Zhang Yan,Zhou Xiao-long,Xie Ming-hua,Liang Xin-qiang,Study on Influence Factors of phosphorus removal by Constructed Wetland,edtied by Environmental Sanitation Engineering1-4(2012). 
[5] Cui Li-hua,Lu Shao-yong,Construction technology of Constructed Wetland for wastewater treatment, edtied by Chemical Industry Press,Beijing (2009) . 